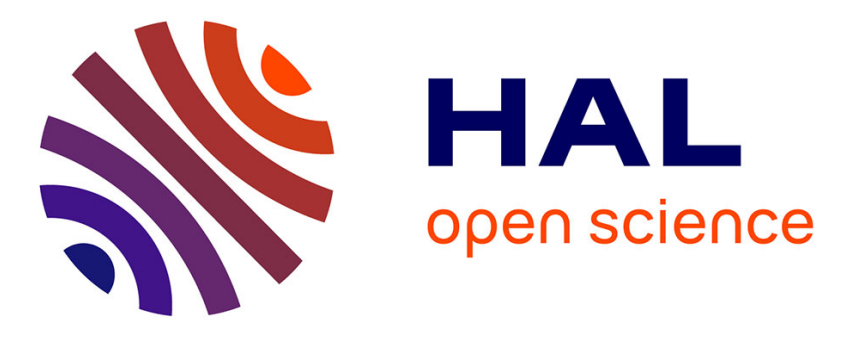

\title{
Base-dependent electron photodetachment from negatively charged DNA strands upon 260-nm laser irradiation
}

Valérie Gabelica, Frédéric Rosu, Thibault Tabarin, Catherine Kinet, Rodolphe Antoine, Michel Broyer, Edwin de Pauw, Philippe Dugourd

\section{To cite this version:}

Valérie Gabelica, Frédéric Rosu, Thibault Tabarin, Catherine Kinet, Rodolphe Antoine, et al.. Basedependent electron photodetachment from negatively charged DNA strands upon 260-nm laser irradiation. Journal of the American Chemical Society, 2007, 129 (15), pp.4706-4713. 10.1021/ja068440z . hal-01524172

\section{HAL Id: hal-01524172 \\ https://hal.science/hal-01524172}

Submitted on 17 May 2017

HAL is a multi-disciplinary open access archive for the deposit and dissemination of scientific research documents, whether they are published or not. The documents may come from teaching and research institutions in France or abroad, or from public or private research centers.
L'archive ouverte pluridisciplinaire HAL, est destinée au dépôt et à la diffusion de documents scientifiques de niveau recherche, publiés ou non, émanant des établissements d'enseignement et de recherche français ou étrangers, des laboratoires publics ou privés. 
This document is the Accepted Manuscript version of a Published Work that appeared in final form in the Journal of the American Chemical Society, copyright (C) American Chemical Society after peer review and technical editing by the publisher. To access the final edited and published work see http://dx.doi.org/10.1021/ja068440z

\title{
Base-Dependent Electron Photodetachment from Negatively Charged DNA Strands upon 260-nm Laser Irradiation
}

Valérie Gabelica ${ }^{1 *}$, Frédéric Rosu ${ }^{1}$, Thibault Tabarin ${ }^{2}$, Catherine Kinet ${ }^{1}$, Rodolphe Antoine ${ }^{2}$, Michel Broyer $^{2}$,Edwin De Pauw ${ }^{1}$, Philippe Dugourd ${ }^{2}$

(1) Laboratoire de Spectrométrie de Masse, Université de Liège, Institut de Chimie, Bat B6c, B-4000 Liège, Belgium, (2) Laboratoire de Spectrométrie Ionique et Moléculaire, UMR 5579 CNRS et Université Lyon 1, 43 Bd du 11 Novembre, F-69622 Villeurbanne, France.

Correspondence: v.gabelica@ulg.ac.be, or dugourd@1asim.univ-lyon1.fr.

\begin{abstract}
DNA multiply charged anions stored in a quadrupole ion trap undergo one-photon electron ejection (oxidation) when subjected to laser irradiation at $260 \mathrm{~nm}(4.77 \mathrm{eV})$. Electron photodetachment is likely a fast process, given that photodetachment is able to compete with internal conversion and/or radiative relaxation to the ground state. The DNA [6-mer] $]^{3-}$ ions studied here show a marked sequence-dependence of electron photodetachment yield. Remarkably, the photodetachment yield $\left(\mathrm{dG}_{6}>\mathrm{dA}_{6}>\mathrm{dC}_{6}>\mathrm{dT}_{6}\right)$ is inversely correlated with the base ionization potentials $(\mathrm{G}<\mathrm{A}<\mathrm{C}<$ $\mathrm{T})$. Sequences with guanine runs show increased photodetachment yield as the number of guanine increases, in line with the fact that positive holes are the most stable in guanine runs. This correlation between photodetachment yield and the stability of the base radical may be explained by tunneling of the electron through the repulsive Coulomb barrier. Theoretical calculations on dinucleotide monophosphates show that the HOMO and HOMO-1 orbitals are localized on the bases. The wavelength-dependence of electron detachment yield was studied for $\mathrm{dG}_{6}^{3-}$. Maximum electron photodetachment is observed in the wavelength range corresponding to base absorption (260-270 $\mathrm{nm}$ ). This demonstrates the feasibility of gas-phase UV spectroscopy on large DNA anions. The calculations and the wavelength dependence suggest that the electron photodetachment is initiated at the bases and not at the phosphates. This also indicates that, although direct photodetachment could also occur, autodetachment from excited states, presumably corresponding to base excitation, is the dominant process at $260 \mathrm{~nm}$. Excited states dynamics of large DNA strands still remains largely unexplored, and photo-oxidation studies on trapped DNA multiply charged anions can help bridging the gap between gas-phase studies on isolated bases or base pairs and solution-phase studies on full DNA strands.
\end{abstract}




\section{Introduction}

The key issue for understanding DNA photostability upon UV irradiation is the nature of the relaxation processes that convert the electronic energy susceptible of causing photochemical reactions into less harmful vibrational energy. Nucleic acids are highly vulnerable in the UVC range of the solar spectrum $(<290 \mathrm{~nm})$, where direct $\pi \pi \rightarrow \pi \pi^{*}$ excitation of the bases occurs. Numerous theoretical ${ }^{1-3}$ and experimenta $1^{4-6}$ studies on excited states relaxation dynamics of isolated bases and base pairs have highlighted very efficient pathways that relax electronic energy to the ground state in less than a picosecond. ${ }^{7-9}$ This fast conversion has been thought to explain the good photostability of DNA bases that were evolutionary selected as the carriers of genetic information. ${ }^{10-12}$ However, the picture gets much more complex when it comes to excited states dynamics of whole DNA strands. The presence of longer-lived (up to nanoseconds) ${ }^{13}$ excited states was revealed in time-resolved spectroscopy studies on DNA single strands and double-strands in solution. The multiple decay pathways and long-lived intermediates encountered in DNA strands compared to isolated nucleobases reveal the high complexity of relaxation mechanisms in these more biologically relevant models. ${ }^{14-18}$ The interpretation of the solution-phase results is also complicated by the intrinsic heterogeneity of the oligonucleotides models exposed to UV irradiation, which can be either conformational heterogeneity, or chemical heterogeneity in the case of photoinduced reactions in the sample during the experiment. ${ }^{19}$

Isolated DNA strands in the gas phase are good models to bridge the gap between molecular beam studies on isolated bases and solution phase studies on full-length DNA. While molecular beams produce neutral molecules, electrospray produces ions directly from the solution by protonation/deprotonation reactions or cation/anion addition. ${ }^{20-22}$ In the case of DNA strands, electrospray produces multiply charged anions by desolvation of the DNA anions that were present in solution. Those negative ions are close to the solution model in the sense that they are closed-shell ions, the multiple charges coming from deprotonation. However, working with anions causes some methodological difficulties. When studying neutral molecules or aggregates, the electronic transitions can be studied with resonant two photon experiments, the second photon leading to the ionization of the molecule, but when the molecules under study are already ionized, other ways of studying electronically excited states must be used, for example via the detection of ion fragmentation. In the field of mass spectrometry, there is currently a renewed interest in photodissociation of electrosprayed ions, pioneered by the group of McLafferty, ${ }^{23,24}$ as a new fragmentation technique for peptides and proteins that leads to new fragmentation channels. ${ }^{25,26}$ In the field of gas-phase spectroscopy, wavelengthresolved photodissociation experiments of electrosprayed ions (usually cations obtained by protonation) have now been reported by several groups, either in the UV-visible range ${ }^{27-35}$, or in the infrared. ${ }^{36-42}$

With the aim of studying electronic excitation of multiply charged DNA anions (single strands and double helices), we started an exploration of the fragmentation pathways by UV irradiation between 220 and $290 \mathrm{~nm}$ (corresponding to absorption of the nucleic bases), and found that the major observable reaction was electron detachment. ${ }^{43}$ Our first study on different DNA single strands and double strands suggested that the electron photodetachment yield was directly dependent on the number of guanines in the strand, and we initially postulated that guanines were mandatory for electron photodetachment to 
occur. ${ }^{43}$ In the present paper, we show that there is a strong dependence of electron photodetachment yield on the base sequence, and that electron detachment yield is inversely correlated to the base ionization potentials. We will discuss the possible electron photodetachment mechanisms, the competition between electron detachment and other fragmentation pathways, and the implications for future DNA photophysics studies.

\section{Experimental section}

Sample preparation. All oligonucleotides used in this study were provided by Eurogentec (Liege, Belgium), with Oligold $\AA$ quality. The oligonucleotides were solubilized in doubly-distilled water to obtain stock solutions with single strand concentration of $200 \mu \mathrm{M}$. Solutions injected in the mass spectrometers were diluted to $25 \mu \mathrm{M}$, in 50/50 (v:v) water/methanol.

Electrospray mass spectrometry and laser irradiation of trapped ions. The experiments were performed on an commercial LCQ Duo quadrupole ion trap mass spectrometer (ThermoFinnigan, San Jose, CA) coupled to a Panther ${ }^{\mathrm{TM}}$ OPO laser pumped by a 355-nm Nd:YAG PowerLite ${ }^{\mathrm{TM}} 8000$ (5 ns pulse width, $20 \mathrm{~Hz}$ repetition rate). Frequency doubling allows scanning in the range $215-300 \mathrm{~nm}$. The standard electrospray source was operated as described previously. ${ }^{43}$ The vacuum chamber and the central ring electrode of the mass spectrometer were modified to allow the injection of UV and visible lights. ${ }^{44}$ A fiber optics glued to the ion trap opposite the incoming beam was used for laser alignment, ensuring reproducible overlap between the laser beam and the ion cloud. An electromechanical shutter triggered on the RF signal of the ion trap synchronizes the laser irradiation with the MS/MS events conducted in the ion trap. To perform laser irradiation for a given number of laser pulses, we add an $\mathrm{MS}^{\mathrm{n}}$ step with activation amplitude of $0 \%$, during which the shutter is open. Therefore, at $20 \mathrm{~Hz}, 50 \mathrm{~ms}$ activation time corresponds to 1 laser pulse, $100 \mathrm{~ms}$ corresponds to 2 laser pulses, etc... The laser power was controlled using a half wave plate and a polarizer, and was monitored with a power meter located just before the injection in the ion trap.

Theoretical calculations. Conformer distributions of the deprotonated dinucleotide monophosphates were obtained from a Monte-Carlo conformational search using Spartan O4 (Wavefunction Inc.) at the semi-empirical AM1 level. For each dinucleotide, two or three significantly different lowest energy conformers were further optimized at the $\mathrm{HF} / 6-31+\mathrm{G}(\mathrm{d}, \mathrm{p})$ level. Correlation energy was taken into account by performing single point calculation at the MP2/6-31+G(d,p) level. The energies of the corresponding neutral radicals were obtained using restricted open shell calculations (ROHF/6$31+\mathrm{G}(\mathrm{d}, \mathrm{p})$ and ROMP2/6-31+G(d,p)) to avoid spin contamination. All electronic structure calculations were performed using the PC GAMESS version 7.0 software. ${ }^{45}$ The molecular orbitals were displayed using Chemcraft (http://www.chemcraftprog.com/) or MOLDEN (http://www.cmbi.ru.nl/molden/molden.html). 


\section{Results and Discussion}

Electron photodetachment from $\mathrm{dG}_{6}{ }^{3-}$ is a one-photon process at $260 \mathrm{~nm}$. In order to get deeper insight into the electron photodetachment mechanism, an important issue is to establish the one-photon or multi-photon character of electron photodetachment observed when using 260-nm (4.77 eV) photons. It must be underlined that we measuring ion yields with the mass spectrometer (signal of radical ion resulting from electron photodetachment relative to the signal of the parent ion), but cannot determine quantum yields directly. The electron detachment ion yield will depends on the electron detachment quantum yield and on the absorption efficiency. We therefore measured the electron detachment ion yield (or simply 'electron detachment yield', as used throughout the forthcoming text) as a function of the laser power for $\mathrm{dG}_{6}{ }^{3-}$, under 1-pulse $(50 \mathrm{~ms})$ and 2-pulse $(100 \mathrm{~ms})$ irradiation. $\mathrm{dG}^{3-}$ was chosen because of its high electron detachment yield, so that electron detachment was detectable even using a single laser pulse at the reduced power obtained after the half wave plate and the polarizer.

Figure 1(A) shows the mass spectrum obtained using a single laser pulse at $3.15 \mathrm{~mJ} / \mathrm{cm}^{2}$. The inset shows the presence of double electron photodetachment in the single-pulse experiments ( 5 ns laser pulse width). Figure 1(B) shows the plot of $\mathrm{I}_{\text {(product) }} / \mathrm{I}_{\text {(precursor) }}$ as a function of the total laser energy for the first electron loss $(3-\rightarrow 2-\bullet)$. The linear increase indicates that the first electron photodetachment is a onephoton process. Red symbols correspond to the same plot for the double electron loss $(3-\rightarrow 1-\bullet \bullet)$. The quadratic increase indicates that this global reaction is a multiphoton process, most likely two-photon. Moreover, the fact that the 1-pulse and 2-pulse data (filled and open symbols, respectively) fall on the same lines, suggests that the consecutive electron photodetachment steps are independent, i.e. $\mathrm{dG}_{6}{ }^{\bullet 1-}$ is produced from $\mathrm{dG}_{6}{ }^{\cdot 2-}$ with equal efficiency either within the $5 \mathrm{~ns}$ single-pulse experiment, or when a second pulse is applied after $50 \mathrm{~ms}$ cooling in the helium bath gas. 

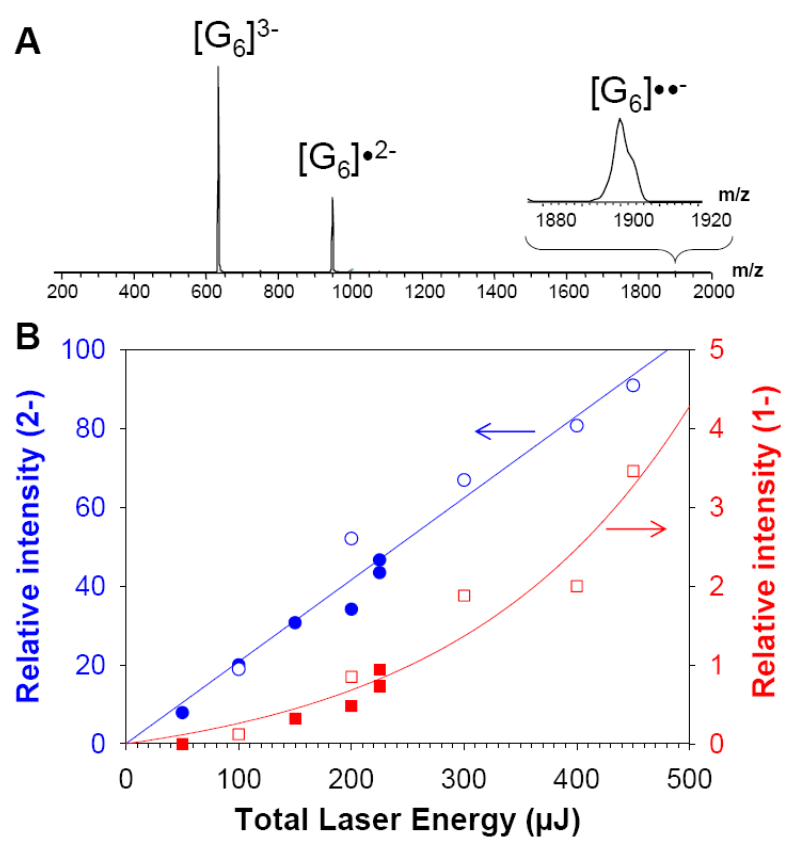

Figure 1. (A) Photodetachment mass spectrum of $\mathrm{dG}^{3-}$ under 1 laser pulse at $260 \mathrm{~nm}$ at $3.15 \mathrm{~mJ} / \mathrm{cm}^{2}$. The inset shows a zoom on the peak corresponding to a double electron detachment. (B) Relative intensities of $\mathrm{dG}_{6}{ }^{-2-}$ (blue, left scale) and $\mathrm{dG}_{6}{ }^{\cdot 1-}$ (red, right scale) produced by laser irradiation of $\mathrm{dG}_{6}^{3-}$ as a function of the total laser fluence. 1-pulse data are represented in full symbols while 2-pulse data are represented in open symbols.

Base-dependence of electron photodetachment yield. The second crucial point for the discussion of the electron photodetachment mechanism is the dependence on the nature of the base. Here we studied DNA 6-mer single strands with various sequences. Figure 2 shows the mass spectra obtained after 1 laser pulse irradiation of the [6-mer $]^{3-}$ anions at $260 \mathrm{~nm}$ for the sequences $\mathrm{G}_{\mathrm{n}} \mathrm{T}_{6-\mathrm{n}}$. These spectra confirm the trend observed previously on DNA duplexes. The strand $\left[\mathrm{T}_{6}\right]^{3-}$ does not encounter electron photodetachment. 

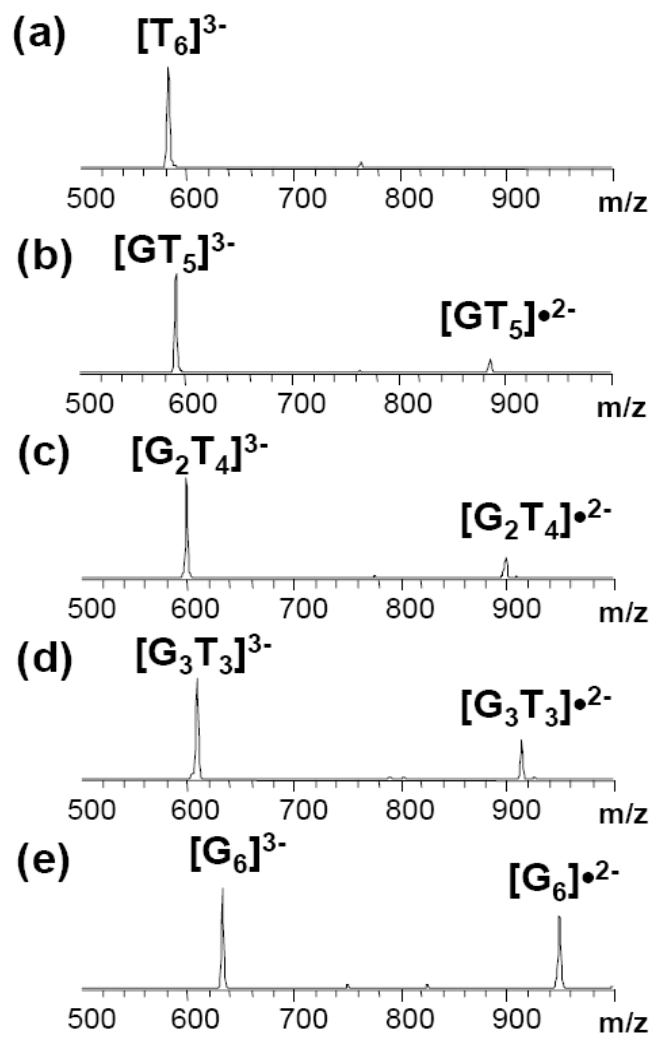

Figure 2. Electron photodetachment as a function of the guanine content: (a) $\left[\mathrm{dT}_{6}\right]^{3-}$, (b) $\left[\mathrm{dGT}_{5}\right]^{3-},(\mathrm{c})$ $\left[\mathrm{dG}_{2} \mathrm{~T}_{4}\right]^{3-},(\mathrm{d}) \mathrm{d}\left[\mathrm{G}_{3} \mathrm{~T}_{3}\right]^{3-}$, and (e) $\left[\mathrm{dG}_{6}\right]^{3-}$. All [6-mers $]^{3-}$ were isolated and subjected to a single 260-nm laser pulse, with identical laser focusing conditions and laser energy (fluence: $11.5 \mathrm{~mJ} / \mathrm{cm}^{2}$ ).

The strong dependence of electron photodetachment yield is in line with a recent photoelectron study on electrosprayed ions that showed specific features at lower electron binding energy in [dGMP-H] ${ }^{-}$and in deprotonated polynucleotides (2/3-mers) containing at least one guanine. ${ }^{46}$ Based on this observation and on DFT calculations of the highest occupied molecular orbitals (HOMOs) of deoxynucleoside monophosphates, the authors concluded that guanine was the site of electron detachment. The strong guanine-dependence of the electron photodetachment yield observed here is in line with the fact that guanine has the lowest ionization potential among all four DNA bases. Recently, several groups reported more advanced calculations of the vertical detachment energies of deoxynucleoside monophosphates, suggesting that the base could play a role in the lowest-energy oxidation in the cases of adenine and thymine as well. ${ }^{47,48}$

In order to try and detect electron detachment in non-guanine containing DNA multiply charged strands, we performed experiments with more than one laser pulse. Figure 3 shows the results obtained for $\left[\mathrm{dG}_{6}\right]^{3-},\left[\mathrm{dA}_{6}\right]^{3-},\left[\mathrm{dC}_{6}\right]^{3-}$ and $\left[\mathrm{dT}_{6}\right]^{3-}$ using 5 laser pulses at $260 \mathrm{~nm}$. Figure 3 shows that $\left[\mathrm{dA}_{6}\right]^{3-}$, and to a lesser extent $\left[\mathrm{dC}_{6}\right]^{3-}$, can also undergo electron photodetachment, while the only visible outcome of $\left[\mathrm{dT}_{6}\right]^{3-}$ irradiation is fragmentation into the so-called a-Base and $\mathrm{w}$ fragments, labeled according to McLuckey's nomenclature. ${ }^{49}$ The competition between electron photodetachment and fragmentation will be discussed in more detail below. Guanine has by far the largest effect on the electron 
photodetachment yield, as shown on Figure 4 where the fraction of surviving parent ion plotted as a function of the number of laser pulses (the slopes of the linear regressions are given in Table 1). A single guanine in the sequence gives a larger electron detachment yield than six adenines.
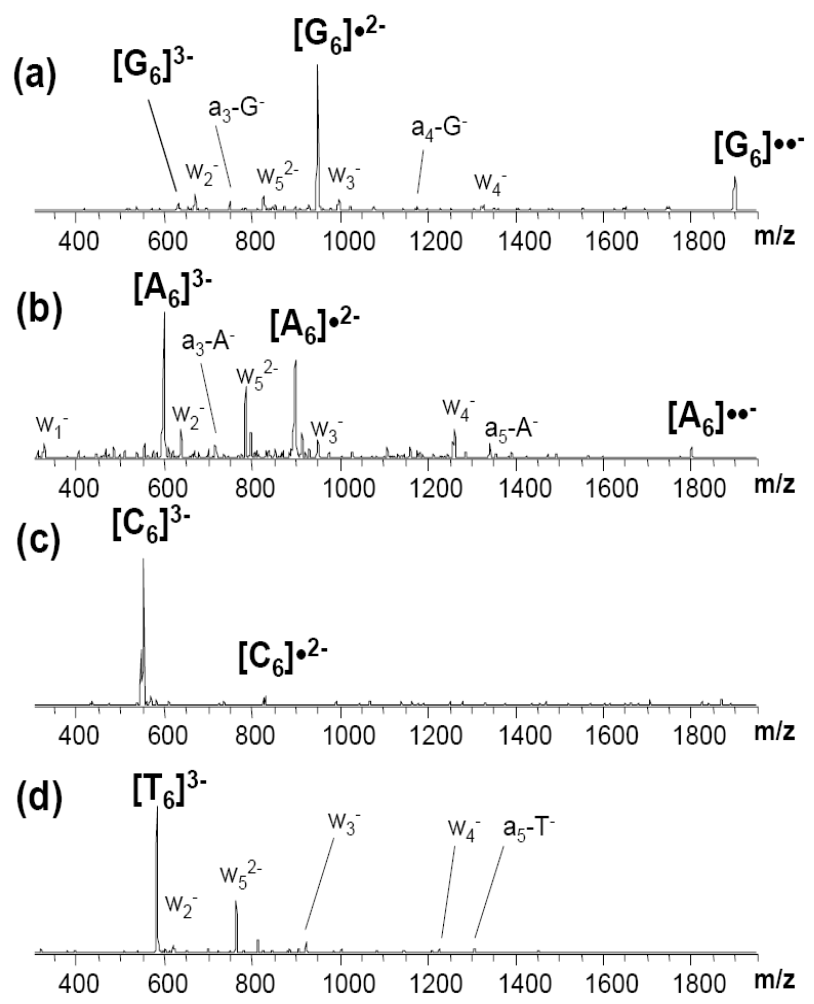

Figure 3. Electron photodetachment and secondary fragmentation as a function of the base: (a) $\left[\mathrm{dG}_{6}\right]^{3-}$, (b) $\left[\mathrm{dA}_{6}\right]^{3-}$, (c) $\left[\mathrm{dC}_{6}\right]^{3-}$, (d) $\left[\mathrm{dT}_{6}\right]^{3-}$. All $\left[\mathrm{dB}_{6}\right]^{3-}$ were isolated and subjected to $250 \mathrm{~ms}$ laser irradiation $(5$ laser pulses) at $260 \mathrm{~nm}$, with identical laser focusing conditions and laser energy (fluence: 11.5 $\left.\mathrm{mJ} / \mathrm{cm}^{2}\right)$. 


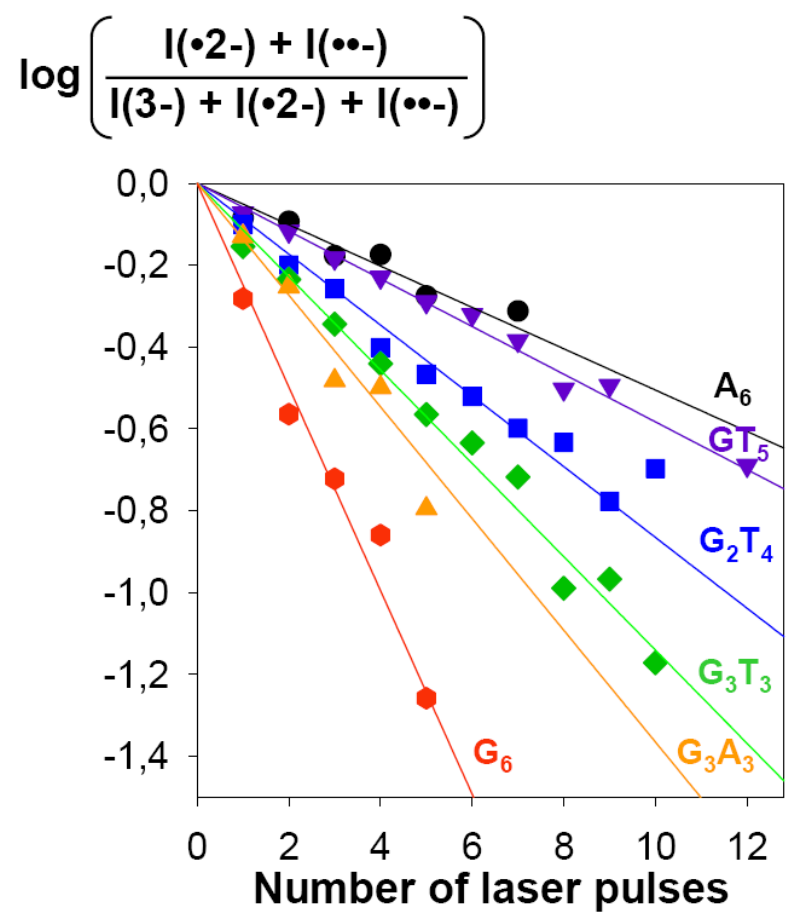

Figure 4. Dependence of electron photodetachment yield on the number of laser pulses as a function of the DNA sequence for [6-mers] $]^{3-}: \mathrm{dA}_{6}$ (black circles), $\mathrm{dGT}_{5}$ (violet down triangles), $\mathrm{dG}_{2} \mathrm{~T}_{4}$ (blue squares), $\mathrm{dG}_{3} \mathrm{~T}_{3}$ (green diamonds), $\mathrm{dG}_{3} \mathrm{~A}_{3}$ (orange up triangles), $\mathrm{dG}_{6}$ (red hexagons).

We therefore investigated which base property(ies) could explain the electron photodetachment yield ordering: $\mathrm{dG}_{6}^{3-}>\mathrm{dA}_{6} 6^{3-}>\mathrm{dC}_{6^{3-}}>\mathrm{dT}_{6} 6^{3-}$. The efficiency of $260-\mathrm{nm}$ photon absorption (oscillator strength) certainly has an influence on the photodetachment yield. This can be approximated by the molar extinction coefficient in solution at $260 \mathrm{~nm},{ }^{50}$ which are given in Table 1 for all strands studied here. If photon absorption efficiency were the only base property controlling photodetachment yield, the ranking would be $\mathrm{A}>\mathrm{G}>\mathrm{T}>\mathrm{C}$. The base-dependence can therefore not be explained by absorption efficiency.

We also included in the study the strand $\mathrm{dG}_{3} \mathrm{~A}_{3}$ for comparison with $\mathrm{dG}_{3} \mathrm{~T}_{3}$, in order to test whether only the number of guanines determines the efficiency of photodetachment after electronic excitation, or whether all bases contributed to the process. However, we are not able to conclude on whether the other bases also have an influence in the presence of guanines because the difference in photodetachment ion yield could be due in this case to the difference in absorption efficiency. 
Table 1. Slopes of the linear regressions shown in Figure 4, and molar extinction coefficients of oligonucleotides in solution at $260 \mathrm{~nm}$.

\begin{tabular}{|l|l|l|}
\hline Sequence & Slope of linear regression & $\varepsilon\left(\mathbf{L} \mathbf{m o l}^{\mathbf{1}} \cdot \mathbf{c m}^{-1}\right) @ \mathbf{2 6 0} \mathbf{~ m m}^{\mathbf{5 0}}$ \\
\hline $\mathrm{dT}_{6}{ }^{3-}$ & 0 & 49200 \\
\hline $\mathrm{dC}_{6}{ }^{3-}$ & n.d. $^{\mathrm{a}}$ & 43400 \\
\hline $\mathrm{dA}_{6}{ }^{3-}$ & $-0.050 \pm 0.010$ & 75400 \\
\hline $\mathrm{dGT}_{5}{ }^{3-}$ & $-0.058 \pm 0.002$ & 52400 \\
\hline $\mathrm{dG}_{2} \mathrm{~T}_{4}{ }^{3-}$ & $-0.087 \pm 0.005$ & 54400 \\
\hline $\mathrm{dG}_{3} \mathrm{~T}_{3}{ }^{3-}$ & $-0.114 \pm 0.006$ & 56400 \\
\hline $\mathrm{dG}_{3} \mathrm{~A}_{3}{ }^{3-}$ & $-0.137 \pm 0.017$ & 69400 \\
\hline $\mathrm{dG}_{6}{ }^{3-}$ & $-0.249 \pm 0.027$ & 62000 \\
\hline
\end{tabular}

${ }^{a}$ Electron detachment is detected but too small to allow quantification and linear regression.

Alternatively, if we consider the potential correlation of electron photodetachment yield with the propensity of the base to lose an electron, we should seek possible correlations with electron detachment energies of DNA bases or DNA strands, base ionization potentials (IP, energy difference between neutral base and the base radical cation) if electron is lost from a neutral base, or base electron affinities (EA, energy difference between the neutral base and the base radical anion), if the electron is lost from a base radical anion. The IP ranking of the neutral bases is $\mathrm{G}<\mathrm{A}<\mathrm{C}<\mathrm{T},{ }^{51,52}$ while the computed electron affinity ranking is $\mathrm{T}>\mathrm{C} \approx \mathrm{G}>\mathrm{A}$ for isolated bases and $\mathrm{dT}>\mathrm{dC}>\mathrm{dG} \approx \mathrm{dA}$ for deoxunucleosides. ${ }^{53}$ The best correlation is therefore found with base ionization potentials, suggesting that the electron photodetachment yield is related to the ability of the neutral bases (the negative charges presumably being located on phosphate groups) to lose an electron. Yang et al. ${ }^{46}$ recently determined adiabatic detachment energies (ADEs) for deprotonated mono-, di-, and trinucleotide, using photoelectron spectroscopy using 157-nm photons. The ADE ordering is $\mathrm{dG}^{-}<\mathrm{dC}^{-}<\mathrm{dT}^{-}<\mathrm{dA}^{-}$for mononucleotides, $\mathrm{dGG}^{-}<\mathrm{dCC}^{-}<\mathrm{dAA}^{-}<\mathrm{dTT}^{-}$for dinucleotides, and $\mathrm{dGGG}^{-}<\mathrm{dAAA}^{-}<\mathrm{dCCC}^{-}<$ dTTT $^{-}$for trinucleotides. For 3-mers on, the electron detachment energies are therefore correlated to the base IPs. For the discussion of the electron photodetachment mechanism, it is tempting to postulate that all these correlations are not fortuitous. 
On the electron photodetachment mechanism. A one-photon oxidation at $260 \mathrm{~nm}(\mathrm{hv}=4.77 \mathrm{eV})$ suggests that electron binding energies $(\mathrm{BE})$ of $\mathrm{dB}_{6}{ }^{3-}$ are $<4.77 \mathrm{eV}$ (except perhaps for $\mathrm{dT}_{6}{ }^{3-}$, for which no photodetachment is observed). This is not surprising in the case of multiply charged anions because of the Coulomb repulsion. Negative electron binding energies are even possible, as shown by a photoelectron spectroscopy study of $\mathrm{dA}_{5}{ }^{4-} .54$ These charge states in the ground electronic state can nevertheless be stable on the time scale of the experiment because of the repulsive Coulomb barrier (RCB). ${ }^{55,56}$ Direct electron photodetachment without transition via a FC state of the closed-shell ion is possible if $h v>\mathrm{RCB}+\mathrm{BE}$. However, an argument in the favor of a major contribution of autodetachment of excited states is the wavelength-dependence of electron detachment yield, which is maximum at wavelengths corresponding to base absorption (see reference 43 and discussion below).

The Franck-Condon (FC) excited states obtained by the initial photon absorption can evolve via the following pathways (Figure 5): internal conversion to the ground state or internal coupling to other excited states E (wavy arrows), radiative decay (dashed arrows) to the ground state, or electron detachment (horizontal dashed arrows). If $h v>\mathrm{RCB}+\mathrm{BE}$ (Figure 5a), electron detachment from the FC state can be very fast. If $\mathrm{BE}<\mathrm{h} v<\mathrm{RCB}+\mathrm{BE}$ (Figure 5b), electron detachment can proceed by tunneling from the FC state through the RCB. If hv $<$ BE, no photodetachment can occur (Figure 5c). While some authors suggested that FC states are delocalized, ${ }^{14,57}$ a recent study suggests that FC states are localized on a base, ${ }^{18}$ and that internal conversion to excimer-like states can occur within $\sim 400$ fs. ${ }^{15,18}$ In the same way, this second excited state E can undergo internal conversion to ground state, radiative decay, electron autodetachment, conversion to another electronic state, etc...

Radiative decay can not be detected in our experimental setup, but internal conversion to the ground state manifests itself by the formation of the a-Base and $\mathrm{w}$ fragments, which are the typical fragments formed by collisional activation of deprotonated closed-shell oligodeoxynucleotides. ${ }^{49}$ The presence of these fragments indicates that a fraction of the electronic energy can be converted into vibrational energy. Total internal conversion to the ground state should be efficient and fast, given the high density of states of these large ions. The very fast pathways demonstrated for isolated bases and base pairs are actually thought to be at the origin of the high photostability of DNA bases. ${ }^{10-12}$ The fact that in most of our experiments electron photodetachment is able to compete with internal conversion is therefore a good indication that electron photodetachment is a fast process initiated by the electronic states attained by the 260-nm photons. Vibrational excitation of the ions would lead to neutral base loss and/or backbone fragmentation on the 50-ms to 500-ms time scale used in our ion trap experiments, but would never lead to electron detachment. It can therefore be concluded that adding $4.77 \mathrm{eV}$ to the closed shell ions in electronic excited states corresponding to base excitation does not produce the same effect as adding $4.77 \mathrm{eV}$ to the closed shell ions in their vibrational modes. The nature of the excited states and how they can promote electron detachment will therefore be briefly discussed in the next section. 

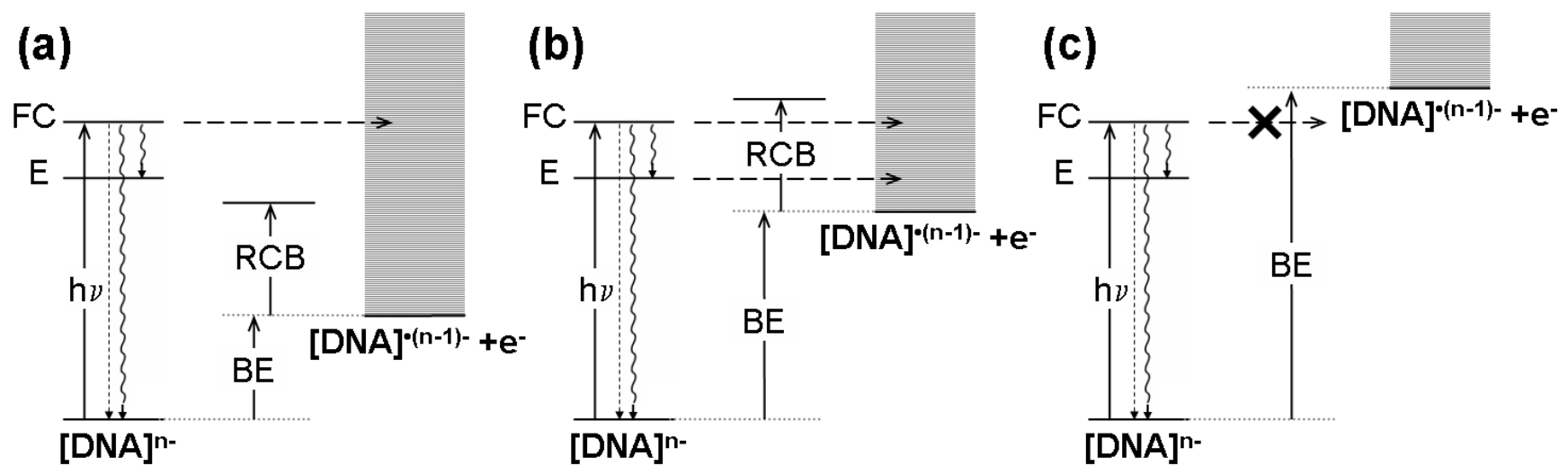

Figure 5. Scheme illustrating the fate of the Franck-Condon (FC) excited state and the possible electron photo detachment pathways. The electron binding energy (BE) is the energy difference between the closed shell multianion $[\mathrm{DNA}]^{\mathrm{n}-}$ and the radical $[\mathrm{DNA}]^{\cdot(\mathrm{n}-1)-}$. The FC state can undergo radiative decay (short dashed arrows), internal conversion to the ground state (long wavy arrows), internal conversion to another electronic excited state E (short wavy arrows), or electron detachment (horizontal long dashed arrows). (a) If $h v>\mathrm{BE}+\mathrm{RCB}$, fast electron photodetachment from the FC state can occur. (b) If $\mathrm{BE}<\mathrm{h} v<\mathrm{BE}+\mathrm{RCB}$, electron autodetachment can occur by tunneling through the repulsive Coulomb barrier, either from the FC state or from another excited state E. (c) If h $v<\mathrm{BE}$, no photodetachment can occur. Note that direct electron photodetachment is not represented here, but is possible if hv $>\mathrm{BE}+$ $\mathrm{RCB}$

It is a reasonable assumption that the magnitude of the repulsive Coulomb barrier can be statedependent because the excited states FC and E can differ by their electronic distribution. For example, state E can involve charge disproportionation (formation of a positive hole on one base and delocalization of an electron). Another possibility that was often mentioned as a possible decay mechanism of excited DNA bases is the conversion of the $\pi \pi^{*}$-like FC state into a $\pi \sigma^{*}$-like state, ${ }^{1,5,58}$ which have a Rydberg character ${ }^{1,2}$ (electron density away from the base). Clearly, the mechanisms by which DNA base excitation stimulates electron detachment needs further investigation, and addressing excited state dynamics in gas phase DNA multiply charged anions is certainly a challenge for the future.

Electron photodetachment experiments like those presented here can however give valuable clues to get some insight in these mechanisms. In particular, the base-dependence of the electron photodetachment yield brings important information. A first possible explanation involves tunneling through the repulsive Coulomb barrier (Figure 5; pathway 1). Such electron tunneling through RCB has been reported previously for linear dicarboxylate dianions. ${ }^{59}$ The tunneling probability depends on the width of the barrier, therefore on the electron binding energy (BE), which is related to the stability of the radical. The correlation with the base IP would therefore imply that the radical in [DNA] ${ }^{(\mathrm{n}-1)-\bullet}$ is localized on a base (positive hole) and not on a phosphate (neutral phosphate $\mathrm{P}-\mathrm{O}^{*}$ ). A second possible explanation of the base-dependence involves internal coupling of the FC state to an electronic excited state characterized by the formation of a positive hole on a base, and electron autodetachment from this 
state (Figure 5; pathway 2). The efficiency of this internal coupling would then be correlated with the stability of a positive hole on a base, and therefore with base IP. In order to decide which explanation is to be preferred, further experiments are planned with strands incorporating modified bases and other chromophores having various charge donor and charge acceptor properties.

In order to refine the photodetachment mechanism and the excited states dynamics, more information is also needed on the time scale of electron photodetachment. The time scale also has important consequences on the potential application of electron photodetachment for performing spectroscopy experiments. Electron detachment channels are advantageous for spectroscopy compared to fragmentation channels because few peaks are observed in the mass spectrum, hence a better sensitivity. If direct electron ejection in the continuum from the FC state were the dominant process, electron photodetachment efficiency would not be wavelength-dependent as long as hv $>\mathrm{BE}+\mathrm{RCB}$. We measured the wavelength-dependence of electron photodetachment yield for the strand with the lowest BE, i.e. $\left[\mathrm{dG}_{6}\right]^{3-}$. The results in Figure 6 shows that electron photodetachment is more efficient in the wavelength range where DNA bases are supposed to absorb, i.e. around 260-270 nm. The involved excited states are therefore sufficiently long-lived to perform spectroscopy. Experiments with higher charge densities (lower RCB) are planned to explore whether direct electron ejection in the continuum could possibly occur in some cases. Furthermore, higher-resolution spectroscopy experiments on cooled ions, and time-resolved measurements are planned to characterize the excited state lifetimes.

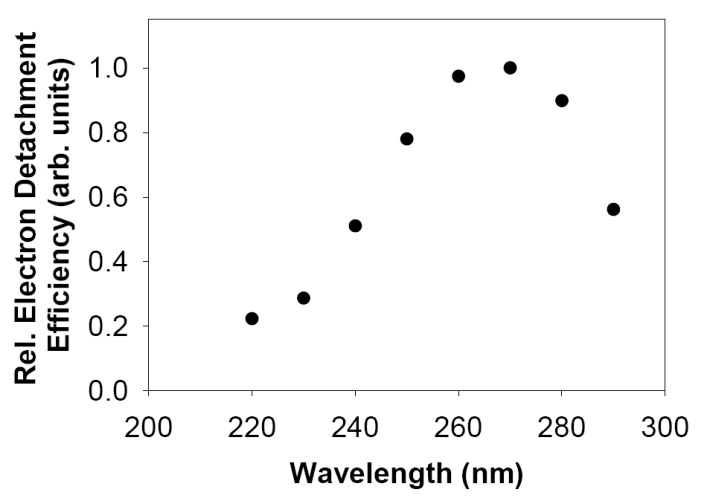

Figure 6. Relative electron photodetachment yield as a function of the wavelength for $\left[\mathrm{dG}_{6}\right]^{3-}$. Electron photodetachment yield was first normalized by the laser fluence and the photon energy, then normalized to unity. 
Theoretical calculations on dinucleotide monophosphates. We also took first steps in the theoretical modeling of longer DNA strands by studying dinucleotide monophosphates. As we observed that the detachment yield strongly depends on the DNA sequence, and in particular on the energy difference between the closed shell multianion and the corresponding radical, we calculated the vertical detachment energies for several dinucleotides, and also examined the highest occupied molecular orbitals (HOMO of the $\mathrm{dBB}^{-}$and $\mathrm{SOMO}$ of the $\mathrm{dBB}^{\circ}$ ). We carried out theoretical calculations of the VDEs of deprotonated dinucleotide monophosphates, first using semi-empirical AM1 level for a Monte Carlo conformational search, then at the $\mathrm{HF}$ 6-31G+(d,p) level for geometry optimization of significantly different low-energy conformers, and finally including a single-point MP2 correction for the electronic energy calculations of the anion and the neutral radical. Computation of the vertical detachment energies (VDEs) of full DNA strands such as those studied here are currently out of range, (1) because vertical detachment energy is an intensive quantity while the total energy is an extensive quantity, ${ }^{60}$ and (2) because, as electron correlation is already crucial in calculating the IPs of isolated DNA bases, ${ }^{61}$ it can certainly not be neglected in the case of full DNA strands, where bases interact with one another.

(A) dGG-

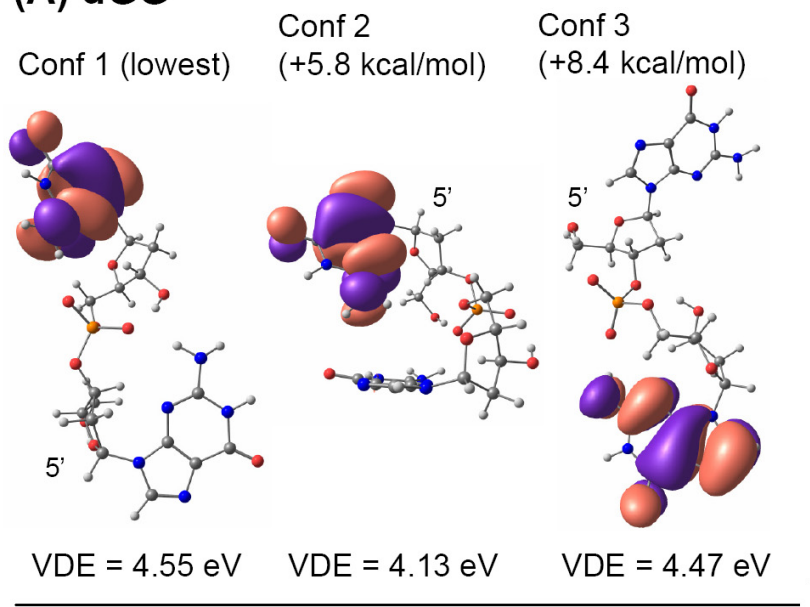

(C) dCG-

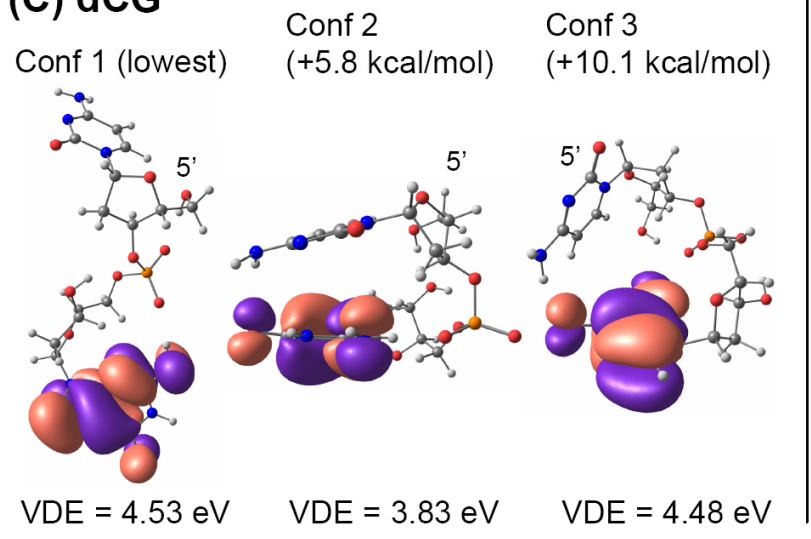

(B) dAA-

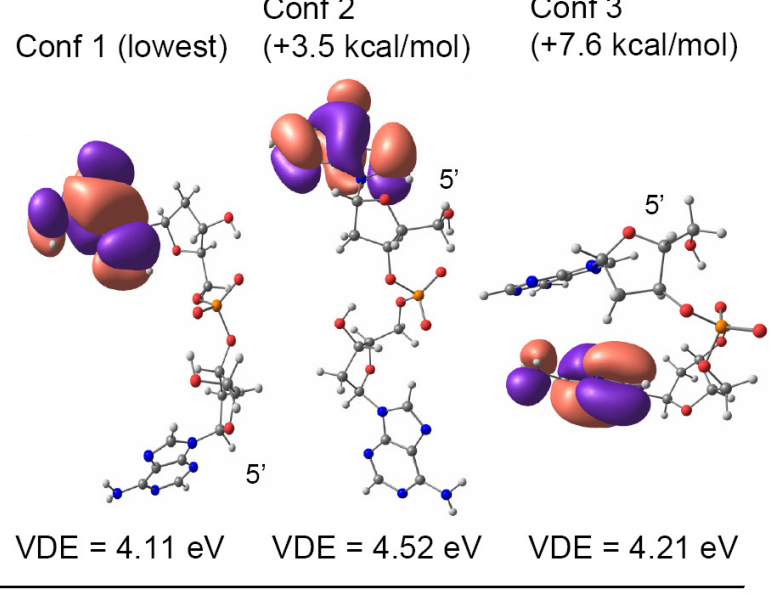

(D) dGT-

Conf 1 (lowest)

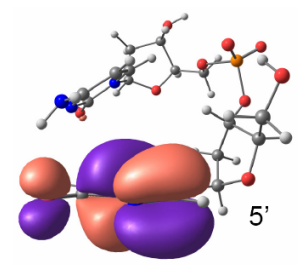

$\mathrm{VDE}=5.58 \mathrm{eV}$
Conf 2

$(+7.0 \mathrm{kcal} / \mathrm{mol})$

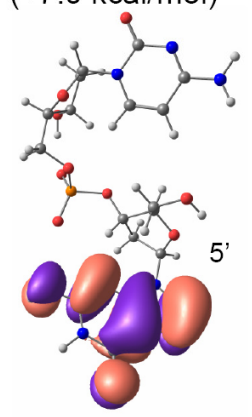

$\operatorname{VDE}=4.29 \mathrm{eV}$

Figure 7. Relative energies (HF 6-31G+(d,p) + MP2 correction), HOMOs (HF 6-31G+(d,p)), and VDEs (HF $6-31 G+(d, p)+M P 2$ correction) of different conformers of the deprotonated dinucleotides monophosphates (A) dGG-, (B) $\mathrm{dAA}^{-},(\mathrm{C}) \mathrm{dCG}^{-}$, and (D) $\mathrm{dGT}^{-}$. 
The HOMOs and VDEs are shown in Figure 7 for several conformers of dGG', $\mathrm{dAA}^{-}, \mathrm{dCG}^{-}$and dGT'. The HOMO-1 to HOMO-4 orbitals of these deprotonated dinucleotides are shown in supplementary information Figures S1-S4, respectively, and the SOMO of the neutral radicals are shown in Figure S5. The lowest energy conformers for $\mathrm{dGG}^{-}, \mathrm{dAA}^{-}$and $\mathrm{dCG}^{-}$are open, while a stacked conformer is the most stable for $\mathrm{dGT}^{-}$, in agreement with Gidden et al. ${ }^{62,63}$ Three lessons can be learned from these calculations:

(1) The HOMO and HOMO-1 are always localized on the bases, as well as the SOMO. When the strand contains only one guanine, the HOMO and SOMO are always localized on this guanine. For the strand dGG, depending on the conformer, the SOMO can be on the other base compared to the HOMO. For the strand dAA, for all three conformers the SOMO is on the other base than the HOMO. Lowest-energy excitations therefore most likely involve the bases rather than the phosphates.

(2) Even though the energies were calculated at the MP2 level, the discrepancies between our calculations and the experimental values ${ }^{46}$ indicate that the computation level is still not high enough. Comparison between MP2 and HF values of the VDEs (provided as supporting information Table S1), indicates that taking into account electron correlation significantly changes VDE, lowering it in nearly all cases.

(3) The VDEs are highly conformation-dependent. Taken together with the previous point, this suggests that geometry optimization too should take electron correlation into account, which makes accurate VDE calculation on polynucleotides really challenging. Our experiments have shown that the photodetachment yield is base-dependent, and that this base-dependence is correlated with the base IP. An important task in the future will be to investigate if this is a baseto-base effect, or a collective effect that would be conformation-dependent. In solution, it has been suggested that hydrogen bonding, and especially base stacking lower the base IP, ${ }^{64-67}$ with the consequence of a significant one-photon component in the photo-oxidation of DNA strands in aqueous solution upon $266 \mathrm{~nm}$ irradiation. ${ }^{68-70} \mathrm{In}$ particular, it has been shown that the IP of guanines was lowered in the interior of guanine runs. ${ }^{66}$ Comparison between solution and gasphase electron photodetachment efficiencies for different DNA structures and the study of the influence of conformation (base stacking or hydrogen bonding) on the electron binding energies of whole DNA strands will therefore help clarifying the DNA photo-oxidation mechanisms.

\section{Comparison between electron photodetachment, thermal autodetachment, and electron} detachment dissociation (EDD). Apart from the photodetachment method discussed here, there are two other ways of detaching electrons from DNA multiply charged ions: thermal autodetachment, ${ }^{71}$ which is obtained when storing the $\mathrm{DNA}^{\mathrm{n}-}$ into a heated ion trap for seconds to minutes, and the interaction of the $\mathrm{DNA}^{\mathrm{n}-}$ with electrons having a kinetic energy of 15 to $18 \mathrm{eV},{ }^{72-74}$ a method known as "electron detachment dissociation", or EDD. In this section we would like to highlight the similarities and differences between photodetachment and these two other methods. 
The most striking difference between photodetachment and thermal detachment is the time scale. Thermal electron detachment time constants were in the order of 1-1000 s for $\mathrm{dB}_{7}$ (3- $\rightarrow$ 2-) for various base sequences between 100 and $150{ }^{\circ} \mathrm{C}$. Anusiewicz and co-authors ${ }^{75}$ proposed that this electron autodetachment from the ground state could be due to geometrical fluctuations of the oligonucleotide causing fluctuations in the Coulomb potential at a phosphate site of sufficient magnitude (estimated as 5 $\mathrm{eV}$, which is the electron binding energy of $\mathrm{H}_{2} \mathrm{PO}_{4}{ }^{-}$) so that the electron can tunnel through the Coulomb barrier, the rate-limiting step being the rate at which geometrical fluctuations bring the oligonucleotide in a favorable conformation for electron autodetachment. The computed electron autodetachment rate of $\mathrm{dT}_{5}{ }^{3-}$ was $0.02-0.5 \mathrm{~s}^{-1}$ at $\mathrm{T}=170{ }^{\circ} \mathrm{C}$. The comparatively very short time scale characterizing electron photodetachment from DNA polyanions under 260-nm laser irradiation is a major difference. In terms of base-dependence, however, there are similarities between photodetachment and thermal detachment. Danell et observed that adenine-containing strands show more efficient electron detachment than thymine-containing strands..$^{54,71}$ The base-dependence was attributed to differences in oligonucleotide

conformational dynamics, ${ }^{54,71,75}$ although the authors did not completely exclude electron detachment from the bases. ${ }^{54}$ Thermal autodetachment from guanine-containing strands was unfortunately not reported. We have seen that the base-dependence can help elucidating the mechanisms of thermal detachment as well.

In electron detachment dissociation (EDD) however, no base-dependence of electron detachment efficiencies was found when comparing $\left[\mathrm{dG}_{6}\right]^{2-},\left[\mathrm{dA}_{6}\right]^{2-},\left[\mathrm{dC}_{6}\right]^{2-}$ and $\left[\mathrm{dT}_{6}\right]^{2-} .{ }^{74}$ The EDD and electron photodetachment mechanisms are therefore different. A possible explanation is that the first step in electron photodetachment involves a base excitation, which triggers electron detachment, while the electron could depart directly from a phosphate in EDD. On an analytical point of view, EDD and photodetachment are complementary, as photodetachment is more efficient than EDD for guaninecontaining strands, while EDD should be preferred for non-guanine containing strands.

\section{Conclusions}

The major findings and implications of the present work on laser irradiation of DNA multiply charged anions with 260-nm (4.77 eV) photons are as follows.

(1) Two detectable competing pathways following 260-nm photon absorption are internal conversion of electronic energy into vibrational energy, which is responsible for formation of a-Base and w fragments, and electron detachment, which is detected by the charge state change. Radiative decay could occur as well, but cannot be detected with our experimental setup.

(2) Electron photodetachment is a one-photon process at $260 \mathrm{~nm}(4.77 \mathrm{eV})$.

(3) The fact that electron photodetachment can compete with excited state relaxation by internal conversion and/or radiative decay suggests that electron detachment must proceed on a short time scale. This contrasts with thermal electron autodetachment from the ground state, which proceeds on time scales from seconds to minutes. 
(4) The yield of electron photodetachment is base-dependent, and increases as the ionization potential (IP) of the base decreases. An increased hole stability therefore increases the probability that electron detachment effectively competes with the other relaxation channels.

(5) This suggests either that electron detachment from the excited state proceeds via tunneling through the repulsive Coulomb barrier, so the tunneling efficiency is related to the stability of the product, or that electron detachment proceeds via an excited state itself involving a positive hole at a base.

(6) The yield of electron photodetachment is wavelength-dependent, with a maximum efficiency in the wavelength range presumably corresponding to DNA base absorption (260-270 nm). Calculations show that the HOMOs of deprotonated dinucleotides, and SOMOs of the corresponding neutral radicals are located on the bases. Altogether, this suggests a mechanism where base excitation triggers electron detachment.

(7) Electron photodetachment can be used as a convenient channel to perform gas-phase spectroscopy studies of nucleic acids, and possibly other biomolecules anions. The approach has been applied already to gas-phase spectroscopy studies of multiply charged transition metal complexes ${ }^{76,77}$ and polypeptides anions. ${ }^{78}$ Future work will be devoted to the study of nucleic acid higher-order structures, and complexes with DNA ligands. We recently found similar electron photodetachment channels for other chromophores bound to DNA strands (Gabelica et al., manuscript in preparation).

\section{Acknowledgements}

The GDR 2758 CNRS «Agrégation, fragmentation et thermodynamique des systèmes complexes isolés » is gratefully acknowledged for financial support. VG is a FNRS research associate and FR is a FNRS post-doctoral fellow (Fonds National de la Recherche Scientifique, Belgium). HP Belgium is gratefully acknowledged for the loan of two linux HP ProLiant ML570 G3 demonstration servers.

\section{Supporting information available}

Table S1 (comparison of VDEs at Koopmans, HF and MP2 level) and Figures S1-S4 (HOMO to HOMO-4 of all dinucleotide models), and Figure S5 (SOMO of the dinucleotide radicals) are provided as supporting information. This material is available free of charge via the Internet at http://pubs.acs.org. 


\section{References}

1. Sobolewski, A. L.; Domcke, W. On the mechanism of nonradiative decay of DNA bases: ab initio and TDDFT results for the excited states of 9H-adenine. Eur. Phys. J. D 2002, 20 (3), 369-374.

2. Shukla, M. K.; Leszczynski, J. TDDFT investigation on nucleic acid bases: Comparison with experiments and standard approach. J. Comput. Chem. 2004, 25 (5), 768-778.

3. Perun, S.; Sobolewski, A. L.; Domcke, W. Ab initio studies on the radiationless decay mechanisms of the lowest excited singlet states of 9H-adenine. J. Am. Chem. Soc. 2005, 127 (17), 6257-6265.

4. Ullrich, S.; Schultz, T.; Zgierski, M. Z.; Stolow, A. Direct observation of electronic relaxation dynamics in adenine via time-resolved photoelectron spectroscopy. J. Am. Chem. Soc. 2004, 126 (8), 2262-2263.

5. Ritze, H. H.; Lippert, H.; Samoylova, E.; Smith, V. R.; Hertel, I. V.; Radloff, W.; Schultz, T. Relevance of pi sigma $(*)$ states in the photoinduced processes of adenine, adenine dimer, and adenine-water complexes. J. Chem. Phys. 2005, 122 (22), 224320.

6. Ullrich, S.; Schultz, T.; Zgierski, M. Z.; Stolow, A. Electronic relaxation dynamics in DNA and RNA bases studied by time-resolved photoelectron spectroscopy. Phys. Chem. Chem. Phys. 2004, 6 (10), 2796-2801.

7. Samoylova, E.; Lippert, H.; Ullrich, S.; Hertel, I. V.; Radloff, W.; Schultz, T. Dynamics of photoinduced processes in adenine and thymine base pairs. J. Am. Chem. Soc. 2005, 127 (6), 1782-1786.

8. Crespo-Hernandez, C. E.; Cohen, B.; Hare, P. M.; Kohler, B. Ultrafast excited-state dynamics in nucleic acids. Chemical Reviews 2004, 104 (4), 1977-2019.

9. Hare, P. M.; Crespo-Hernandez, C. E.; Kohler, B. Internal conversion to the electronic ground state occurs via two distinct pathways for pyrimidine bases in aqueous solution. Proc. Natl. Acad. Sci. U. S A 2007, 104, 435-440. 
10. Satzger, H.; Townsend, D.; Zgierski, M. Z.; Patchkovskii, S.; Ullrich, S.; Stolow, A. Primary processes underlying the photostability of isolated DNA bases: Adenine. Proc. Natl. Acad. Sci. USA 2006, 103 (27), 10196-10201.

11. Sobolewski, A. L.; Domcke, W.; Hattig, C. Tautomeric selectivity of the excited-state lifetime of guanine/cytosine base pairs: The role of electron-driven proton-transfer processes. Proc. Natl. Acad. Sci. USA 2005, 102 (50), 17903-17906.

12. Schultz, T.; Samoylova, E.; Radloff, W.; Hertel, I. V.; Sobolewski, A. L.; Domcke, W. Efficient deactivation of a model base pair via excited-state hydrogen transfer. Science 2004, 306 (5702), 1765-1768.

13. Plessow, R.; Brockhinke, A.; Eimer, W.; Kohse-Hoinghaus, K. Intrinsic Time- and WavelengthResolved Fluorescence of Oligonucleotides: A Systematic Investigation Using a Novel Picosecond Laser Approach. J. Phys. Chem. B 2000, 104 (15), 3695-3704.

14. Markovitsi, D.; Onidas, D.; Gustavsson, T.; Talbot, F.; Lazzarotto, E. Collective behavior of Franck-Condon excited states and energy transfer in DNA double helices. J. Am. Chem. Soc. 2005, 127 (49), 17130-17131.

15. Crespo-Hernandez, C. E.; Cohen, B.; Kohler, B. Base stacking controls excited-state dynamics in A-T DNA. Nature 2005, 436 (7054), 1141-1144.

16. Markovitsi, D.; Talbot, F.; Gustavsson, T.; Onidas, D.; Lazzarotto, E.; Marguet, S. Molecular spectroscopy: Complexity of excited-state dynamics in DNA. Nature 2006, 441 (7094), E7.

17. Crespo-Hernandez, C. E.; Cohen, B.; Kohler, B. Molecular spectroscopy: Complexity of excited-state dynamics in DNA - Reply. Nature 2006, 441 (7094), E8.

18. Kwok, W. M.; Ma, C.; Phillips, D. L. Femtosecond Time- and Wavelength-Resolved Fluorescence and Absorption Spectroscopic Study of the Excited States of Adenosine and an Adenine Oligomer. J. Am. Chem. Soc. 2006, 128 (36), 11894-11905.

19. Markovitsi, D.; Onidas, D.; Talbot, F.; Marguet, S.; Gustavsson, T.; Lazzarotto, E. UVB/UVC induced processes in model DNA helices studied by time-resolved spectroscopy: Pitfalls and tricks. J. Photochem. Photobiol. A 2006, 183, 1-8. 
20. Fenn, J. B.; Mann, M.; Meng, C. K.; Wong, S. F.; Whitehouse, C. M. Electrospray ionization for mass spectrometry. Science 1989, 246, 64-71.

21. Fenn, J. B.; Mann, M.; Meng, C. K.; Wong, S. F. Electrospray ionization-principles and practice. Mass Spectrom. Rev. 1990, 9, 37-70.

22. Cech, N. B.; Enke, C. G. Practical implications of some recent studies in electrospray ionization fundamentals. Mass Spectrom. Rev. 2001, 20, 362-387.

23. Williams, E. R.; Furlong, J. J. P.; McLafferty, F. W. Efficiency of Collisionally-Activated Dissociation and 193-Nm Photodissociation of Peptide Ions in Fourier-Transform MassSpectrometry. J. Am. Soc. Mass Spectrom. 1990, 1 (4), 288-294.

24. Guan, Z.; Kelleher, N. L.; O'Connor, P. B.; Aaserud, D. J.; Little, D. P.; McLafferty, F. W. 193 $\mathrm{nm}$ photodissociation of larger multiply-charged biomolecules. Int. J. Mass Spectrom. Ion. Proc. 1996, 157-158, 357-364.

25. Kim, T. Y.; Thompson, M. S.; Reilly, J. P. Peptide photodissociation at $157 \mathrm{~nm}$ in a linear ion trap mass spectrometer. Rapid Commun. Mass Spectrom. 2005, 19 (12), 1657-1665.

26. Moon, J. H.; Yoon, S. H.; Kim, M. S. Photodissociation of singly protonated peptides at $193 \mathrm{~nm}$ investigated with tandem time-of-flight mass spectrometry. Rapid Commun. Mass Spectrom. 2005, 19 (22), 3248-3252.

27. Nolting, D.; Marian, C.; Weinkauf, R. Protonation effect on the electronic spectrum of tryptophan in the gas phase. Phys. Chem. Chem. Phys. 2004, 6 (10), 2633-2640.

28. Marian, C.; Nolting, D.; Weinkauf, R. The electronic spectrum of protonated adenine: Theory and experiment. Phys. Chem. Chem. Phys. 2005, 7 (18), 3306-3316.

29. Andersen, L. H.; Heber, O.; Zajfman, D. Physics with electrostatic rings and traps. J. Phys. B-At. Mol. Opt. Phys. 2004, 37 (11), R57-R88.

30. Nielsen, S. B.; Lapierre, A.; Andersen, J. U.; Pedersen, U. V.; Tomita, S.; Andersen, L. H. Absorption spectrum of the green fluorescent protein chromophore anion in vacuo. Phys. Rev. Lett. 2001, 8722 (22).

31. Andersen, L. H.; Lapierre, A.; Nielsen, S. B.; Nielsen, I. B.; Pedersen, S. U.; Pedersen, U. V.; Tomita, S. Chromophores of the green fluorescent protein studied in the gas phase. Eur. Phys. J. D 2002, 20 (3), 597-600. 
32. Talbot, F. O.; Tabarin, T.; Antoine, R.; Broyer, M.; Dugourd, P. Photodissociation spectroscopy of trapped protonated tryptophan. J. Chem. Phys. 2005, 122 (7).

33. Tabarin, T.; Antoine, R.; Broyer, M.; Dugourd, P. Specific photodissociation of peptides with multi-stage mass spectrometry. Rapid Commun. Mass Spectrom. 2005, 19 (20), 28832892.

34. Kang, H.; Jouvet, C.; donder-Lardeux, C.; Martrenchard, S.; Gregoire, G.; Desfrancois, C.; Schermann, J. P.; Barat, M.; Fayeton, J. A. Ultrafast deactivation mechanisms of protonated aromatic amino acids following UV excitation. Phys. Chem. Chem. Phys. 2005, 7 (2), 394-398.

35. Boyarkin, O. V.; Mercier, S. R.; Kamariotis, A.; Rizzo, T. R. Electronic spectroscopy of cold, protonated tryptophan and tyrosine. J. Am. Chem. Soc. 2006, 128 (9), 2816-2817.

36. Oomens, J.; Polfer, N.; Moore, D. T.; van der Meer, L.; Marshall, A. G.; Eyler, J. R.; Meijer, G.; von Helden, G. Charge-state resolved mid-infrared spectroscopy of a gas-phase protein. Phys. Chem. Chem. Phys. 2005, 7 (7), 1345-1348.

37. Oh, H. B.; Lin, C.; Hwang, H. Y.; Zhai, H. L.; Breuker, K.; Zabrouskov, V.; Carpenter, B. K.; McLafferty, F. W. Infrared photodissociation spectroscopy of electrosprayed ions in a Fourier transform mass spectrometer. J. Am. Chem. Soc. 2005, 127 (11), 4076-4083.

38. Polfer, N. C.; Valle, J. J.; Moore, D. T.; Oomens, J.; Eyler, J. R.; Bendiak, B. Differentiation of isomers by wavelength-tunable infrared multiple-photon dissociation-mass spectrometry: Application to glucose-containing disaccharides. Anal. Chem. 2006, 78 (3), 670-679.

39. Simon, A.; Jones, W.; Ortega, J. M.; Boissel, P.; Lemaire, J.; Maitre, P. Infrared multiphoton dissociation spectroscopy of gas-phase mass-selected hydrocarbon-Fe+ complexes. $J$. Am. Chem. Soc. 2004, 126 (37), 11666-11674.

40. Polfer, N. C.; Oomens, J.; Dunbar, R. C. IRMPD spectroscopy of metal-ion/tryptophan complexes. Phys. Chem. Chem. Phys. 2006, 8 (23), 2744-2751.

41. Polfer, N. C.; Paizs, B.; Snoek, L. C.; Compagnon, I.; Suhai, S.; Meijer, G.; von Helden, G.; Oomens, J. Infrared fingerprint spectroscopy and theoretical studies of potassium ion tagged amino acids and peptides in the gas phase. J. Am. Chem. Soc. 2005, 127 (23), 8571-8579. 
42. Kamariotis, A.; Boyarkin, O. V.; Mercier, S. R.; Beck, R. D.; Bush, M. F.; Williams, E. R.; Rizzo, T. R. Infrared spectroscopy of hydrated amino acids in the gas phase: Protonated and lithiated valine. J. Am. Chem. Soc. 2006, 128 (3), 905-916.

43. Gabelica, V.; Tabarin, T.; Antoine, R.; Rosu, F.; Compagnon, I.; Broyer, M.; De Pauw, E.; Dugourd, P. Electron Photodetachment Dissociation of DNA Polyanions in a Quadrupole Ion Trap Mass Spectrometer. Anal. Chem. 2006, 78 (18), 6564-6572.

44. Dugourd, P.; Antoine, R.; Broyer, M.; Talbot, F. O. International patent WO 2006064132, 2006.

45. Granovsky, A. A. PC Gamess v. 7.0. http://classic. chem. msu. su/gran/gamess/index. html 2006.

46. Yang, X.; Wang, X. B.; Vorpagel, E. R.; Wang, L. S. Direct experimental observation of the low ionization potentials of guanine in free oligonucleotides by using photoelectron spectroscopy. Proc. Natl. Acad. Sci. U. S A 2004, 101 (51), 17588-17592.

47. Rubio, M.; Roca-Sanjuan, D.; Merchan, M.; Serrano-Andres, L. Determination of the lowestenergy oxidation site in nucleotides: 2 '-Deoxythymidine 5 '-monophosphate anion. $J$. Phys. Chem. B 2006, 110 (21), 10234-10235.

48. Zakjevskii, V. V.; King, S. J.; Dolgounitcheva, O.; Zakrzewski, V. G.; Ortiz, J. V. Base and Phosphate Electron Detachment Energies of Deoxyribonucleotide Anions. J. Am. Chem. Soc. 2006, 128 (41), 13350-13351.

49. Wu, J.; McLuckey, S. A. Gas-phase fragmentation of oligonucleotide ions. Int. J. Mass Spectrom. 2004, 237 (2-3), 197-241.

50. Handbook of Biochemistry and Molecular Biology; 3rd Edition ed.; CRC Press: 1975; Vol. Volume 1: Nucleic Acids.

51. Hush, N. S.; Cheung, A. S. Ionization potentials and donor properties of nucleic adic bases and related compounds. Chem. Phys. Lett. 1975, 34 (1), 11-13.

52. Orlov, V. N.; Smirnov, A. N.; Varshavsky, Y. M. Ionization potentials and electron-donor ability of nucleic acid bases and their analogues. Tetrahedron Lett. 1976, 48, 4377-4378.

53. Richardson, N. A.; Gu, J.; Wang, S.; Xie, Y.; Schaeffer III, H. F. DNA nucleosides and their radical anions: molecular structures and electron affinities. J. Am. Chem. Soc. 2004, 126, 4404-4411. 
54. Weber, J. M.; Ioffe, I. N.; Berndt, K. M.; Loffler, D.; Friedrich, J.; Ehrler, O. T.; Danell, A. S.; Parks, J. H.; Kappes, M. M. Photoelectron spectroscopy of isolated multiply negatively charged oligonucleotides. J. Am. Chem. Soc. 2004, 126 (27), 8585-8589.

55. Dreuw, A.; Cederbaum, L. S. Multiply charged anions in the gas phase. Chemical Reviews 2002, 102 (1), 181-200.

56. Simons, J. Anions. In Encyclopedia of Mass Spectrometry Volume 1: Theory and Ion Chemistry, 1st Edition ed; Armentrout, P. B., Ed.; Elsevier: 2003; pp 55-68.

57. Emanuele, E.; Zakrzewska, K.; Markovitsi, D.; Lavery, R.; Millie, P. Exciton states of dynamic DNA double helices: Alternating dCdG sequences. J. Phys. Chem. B 2005, 109 (33), 16109-16118.

58. Sobolewski, A. L.; Domcke, W.; Dedonder-Lardeux, C.; Jouvet, C. Excited-state hydrogen detachment and hydrogen transfer driven by repulsive (1)pi sigma* states: A new paradigm for nonradiative decay in aromatic biomolecules. Phys. Chem. Chem. Phys. 2002, 4 (7), 1093-1100.

59. Wang, L. S.; Li, X.; Zhang, H. F. Probing the electronic structure of iron clusters using photoelectron spectroscopy. Chemical Physics 2000, 262 (1), 53-63.

60. Simons, J. Response of a molecule to adding or removing an electron. Advances in Quantum Chemistry, Vol 50 2005, 50, 213-233.

61. Cauet, E.; Dehareng, D.; Lievin, J. Ab initio study of the ionization of the DNA bases: Ionization potentials and excited states of the cations. J. Phys. Chem. A 2006, 110 (29), 9200-9211.

62. Gidden, J.; Bushnell, J. E.; Bowers, M. T. Gas-phase conformations and folding energetics of oligonucleotides: $\mathrm{dTG}^{-}$and $\mathrm{dGT}^{-}$. J. Am. Chem. Soc. 2001, 123, 5610-5611.

63. Gidden, J.; Bowers, M. T. Gas-phase conformational and energetic properties of deprotonated dinucleotides. European Physical Journal D 2002, 20 (3), 409-419.

64. Sugiyama, H.; Saito, I. Theoretical studies of GC-specific photocleavage of DNA via electron transfer: Significant lowering of ionization potential and 5'-localization of HOMO of stacked GG bases in B-form DNA. J. Am. Chem. Soc. 1996, 118 (30), 7063-7068. 
65. Kim, N. S.; Zhu, Q. Q.; LeBreton, P. R. Aqueous ionization and electron-donating properties of dinucleotides: Sequence-specific electronic effects on DNA alkylation. J. Am. Chem. Soc. 1999, 121 (49), 11516-11530.

66. Zhu, Q. Q.; LeBreton, P. R. DNA photoionization and alkylation patterns in the interior of guanine runs. J. Am. Chem. Soc. 2000, 122 (51), 12824-12834.

67. Starikov, E. B.; Lewis, J. P.; Sankey, O. F. Base sequence effects on charge carrier generation in DNA: A theoretical study. Int. J. Mod. Phys. B 2005, 19 (29), 4331-4357.

68. Crespo-Hernandez, C. E.; Arce, R. Photoionization of DNA and RNA bases, nucleosides and nucleotides through a combination of one- and two-photon pathways upon $266 \mathrm{~nm}$ nanosecond laser excitation. Photochemistry and Photobiology 2002, 76 (3), 259-267.

69. Crespo-Hernandez, C. E.; Arce, R. Near threshold photo-oxidation of dinucleotides containing purines upon $266 \mathrm{~nm}$ nanosecond laser excitation. The role of base stacking, conformation, and sequence. J. Phys. Chem. B 2003, 107 (4), 1062-1070.

70. Marguet, S.; Markovitsi, D.; Talbot, F. One- and two-photon ionization of DNA single and double helices studied by laser flash photolysis at $266 \mathrm{~nm}$. J. Phys. Chem. B 2006, 110 (23), 11037-11039.

71. Danell, A. S.; Parks, J. H. Fraying and electron autodetachment dynamics of trapped gas phase oligonucleotides. J. Am. Soc. Mass Spectrom. 2003, 14 (12), 1330-1339.

72. Yang, J.; Mo, J. J.; Adamson, J. T.; Hakansson, K. Characterization of oligodeoxynucleotides by electron detachment dissociation Fourier transform ion cyclotron resonance mass spectrometry. Anal. Chem. 2005, 77 (6), 1876-1882.

73. Mo, J.; Hakansson, K. Characterization of nucleic acid higher order structure by high-resolution tandem mass spectrometry. Anal. Bioanal. Chem. 2006, 386 (3), 675-681.

74. Yang, J.; Hakansson, K. Fragmentation of oligoribonucleotides from gas-phase ion-electron reactions. J. Am. Soc. Mass Spectrom. 2006, 17 (10), 1369-1375.

75. Anusiewicz, W.; Berdys-Kochanska, J.; Czaplewski, C.; Sobczyk, M.; Daranowski, E. M.; Skurski, P.; Simons, J. Charge loss in gas-phase multiply negatively charged oligonucleotides. J. Phys. Chem. A 2005, 109 (1), 240-249. 
76. Kordel, M.; Schooss, D.; Gilb, S.; Blom, M. N.; Hampe, O.; Kappes, M. M. Photodissociation of trapped metastable multiply charged anions: A routine electronic spectroscopy of isolated large molecules? J. Phys. Chem. A 2004, 108 (22), 4830-4837.

77. Loffler, D.; Weber, J. M.; Kappes, M. M. Photodetachment spectroscopy of PtBr42-: Probing the Coulomb barrier of a doubly charged anion. J. Chem. Phys. 2005, 123 (22), 224308.

78. Antoine, R.; Joly, L.; Tabarin, T.; Broyer, M.; Dugourd, P.; Lemoine, J. Photo-induced formation of radical anion peptides. Electron photo-detachment dissociation experiments. Rapid Commun. Mass Spectrom. 2007, 21, 265-268. 